Published in final edited form as:

Curr Opin Hematol. 2013 July ; 20(4): 295-300. doi:10.1097/MOH.0b013e3283615aba.

\title{
Cdc42 and aging of hematopoietic stem cells
}

\author{
Hartmut Geigera,b and Yi Zheng ${ }^{a}$ \\ aDepartment of Dermatology and Allergic Diseases, University of Ulm, Ulm, Germany \\ bDivision of Experimental Hematology and Cancer Biology, Cincinnati Children's Hospital Medical \\ Center and University of Cincinnati, Cincinnati, Ohio, USA
}

\begin{abstract}
Purpose of review-Hematopoietic stem cells (HSCs) continuously provide mature blood cells during the lifespan of a mammal. The functional decline in hematopoiesis in the elderly, which involves a progressive reduction in the immune response and an increased incidence of myeloid malignancy, is partly linked to HSC aging. Molecular mechanisms of HSC aging remain unclear, hindering rational approaches to slow or reverse the decline of HSC function with age. Identifying conditions under which aged HSCs become equivalent to young stem cells might result in treatments for age-associated imbalances in lymphopoiesis and myelopoiesis and in blood regeneration.
\end{abstract}

Recent findings-Aging of HSCs has been for a long time thought to be an irreversible process imprinted in stem cells due to the intrinsic nature of HSC aging. Mouse model studies have found that aging is associated with elevated activity of the Rho GTPase Cdc42 in HSCs that is causative for loss of polarity, altered epigenetic modifications and functional deficits of aged HSCs. The work suggests that inhibition of Cdc42 activity in aged HSCs may reverse a number of phenotypes associated with HSC aging.

Summary-Maintaining the regenerative capacity of organs or organ systems may be a useful way to ensure healthy aging. A defined set of features phenotypically separate young from aged HSCs. Aging of HSCs has been thought to be irreversible. Recent findings support the hypothesis that functional decline of aged HSCs may be reversible by pharmacological intervention of age altered signaling pathways and epigenetic modifications.

\section{Keywords}

aging; Cdc42; HSC; polarity; rejuvenation

\section{(C) 2013 Wolters Kluwer Health | Lippincott Williams \& Wilkins}

Correspondence to Hartmut Geiger, Cincinnati Children's Hospital Medical Center, Cincinnati, OH 45229, USA. Tel: +1 513 636 1338; fax: +1 513636 3768; hartmut.geiger@uni-ulm.de.

Conflicts of interest

There are no conflicts of interest. 


\section{INTRODUCTION}

The demographic development in most Western countries shows that age-associated diseases and their prevention are becoming an important social, economic and medical issue. The trend in population aging is unprecedented, without parallel in human history, and the twenty-first century will witness even more rapid aging than did the century just past (http:// www.un.org/esa/population/publications/worldageing19502050).

Improved and in-depth knowledge on molecular and cellular mechanisms of aging are the basis for designing rational approaches and future therapies to allow for healthy aging. Aging results in progressive loss of function of distinct cells and organ systems as well as reduced regenerative function, and thus impaired tissue homeostasis. This results in an increase in morbidity and mortality with age, and it is assumed that aging of whole organs limits lifespan. Maintaining the regenerative capacity of organs or organ systems might, thus, become a useful way to ensure healthy aging [1]. The mechanisms of age-associated diseases appear complex and multifactorial, and they are frequently controversially discussed [2-8].

\section{AGING OF HEMATOPOIETIC STEM CELLS}

Several theories regarding regulation of aging have been postulated, and genetic, behavioral and environmental factors are all thought to be involved [9]. Evidence accumulated over the past decade has shown measurable and successive age-dependent decline in stem cell activity from adulthood to old age - in various organ systems, including hematopoietic, intestinal and muscle. The age-associated changes in stem cell function may lead to a decline in the regenerative capacity in humans and mice [4,10-15], which may limit lifespan $[4,10,16-18]$. Identifying conditions under which aged stem cells are activated to become phenotypically and functionally equivalent to young stem cells could be a first step toward designing future treatment strategies for age-associated imbalances in tissue homeostasis and tissue regeneration, thereby allowing for healthy aging.

HSCs from young and aged mice differ in their function. Changes in the number of HSCs with age are strain-dependent in mice: in C57BL/6 mice, for example, HSC number increases with age, in contrast to other strains such as DBA/2. Independent of animal genotypes, though, aging exerts a deleterious effect on HSC self-renewal and differentiation activities. In principle, HSC aging can be regulated by both intrinsic and extrinsic factors [4,7,19-23], One one hand, aged HSCs show reduced self-renewal activity determined in serial transplant assays [24]. When aged HSCs are transplanted together with young HSCs into lethally irradiated young recipients, aged HSCs are on average two-fold less efficient in contributing to hematopoiesis compared with young HSCs $[25,26]$ and exhibit a two-fold reduced activity in homing to the bone marrow [27]. On the other hand, aging also affects the differentiation potential of HSCs. Studies have demonstrated that aged HSCs are deficient in their ability to support erythropoiesis, and that aged HSCs do not efficiently generate B-lymphoid progeny but better in supporting the myeloid cell lineage (see [28] and references cited in there). Aged HSCs exhibit distinct whole genome expression signatures $[20,29]$ and increased double-strand breaks as detected by increased levels of gammaH2AX 
staining, a surrogate marker for DNA double strand breaks [30], from young HSCs. Aged HSCs are less efficient in their ability to adhere to stroma cells and exhibit significantly elevated cell protrusion activity in vivo, potentially reducing the time for effective interactions with the microenvironment [31-33].

Cell polarity is well characterized in epithelial cells (termed planar cell polarity $[34,35]$ ) and neuronal stem cells, but was only recently described by us and others to also exist in HSCs $\left[36^{\mathbf{*}}, 37^{\boldsymbol{*}}, 38\right]$. Asymmetric distribution of cellular components upon division in HSCs was shown by single-cell immunostaining $[39,40]$ and a fluorescent Notch-activity indicator system [37",41,42"'] that is most likely a consequence of cell-polarity. Recent studies have found that aged HSCs present with an apolar distribution of planar cell polarity markers such as Cdc42 or Scribble as well as histone 4 acetylated at lysine 16 within the nucleus (epipolarity). Interestingly, some markers for epithelial planar cell polarity, for example atypical protein kinase C, are apolar in young HSCs [43], suggesting HSC-specific features of polarity regulation. Thus, a defined set of features allows phenotypic distinction of young HSCs from aged HSCs. Supporting a causal role of polarity in stem cell maintenance and aging is a recent study showing that loss of polarity in Drosophila germ-line stem cells correlates with a reduced function $[44,45]$. Recent evidence also suggests that the hematopoietic system might be maintained by a consortium of HSC subtypes (myeloidbiased HSCs and lymphoid-biased HSCs) that can be prospectively purified, and that aging changes the clonal composition of the HSC compartment because of a relative expansion of myeloid-biased HSCs (clonal diversity/expansion model) [36",46-49]. These subtypes are not linked to the polarity phenotype while there is further evidence that also these subtypes present with a functional decline with aging [50], and thus aging might be combination of stem cell aging and clonal shifts.

Recently published data also support an important role for HSC regulation via metabolic pathways as well as autophagy via FOXO3A [51,52]. As the metabolic insulin-like growth factor 1 (IGF1) signaling pathway, also via FOXO proteins, plays an important role in lifespan regulation in at least lower organisms, it is an interesting hypothesis that aging of HSCs might also be linked to changes in metabolic or autophagy pathways.

In addition to intrinsic cues, aging of HSCs can also be influenced by extrinsic signals stemming from the bone marrow niche. For example, enhanced cytokine signaling can counteract age-related HSC functional decline in the setting of loss of lymphocyte-specific adapter protein (LNK) deficiency in stem cells [53"], whereas in the absence of the GAP junction formed by Connexin 43, HSCs are defective in unloading their reactive oxygen species onto niche cells and maintaining proper homeostasis under stress [54]. It is an intriguing possibility that niche factors might influence aging and clonality of HSCs and aging-associated progression of leukemia [54,55"].

\section{MECHANISMS LINKED TO THE AGING OF HEMATOPOIETIC STEM CELLS}

Despite extensive efforts in this field, detailed molecular mechanisms of HSC aging remain elusive. Contribution to aging by some obvious molecular events, such as oxidative stressinduced acquisition of defects in genomic, telomeric and/or mitochondrial DNA as well as 
DNA repair machineries [56-60], are supported by the fact that aged HSCs show increased DNA double strand breaks [30]. In support of an involvement of oxidative stress, phenotypes associated with aged HSCs could be partially ameliorated by antioxidant therapy [61], and deficiencies in DNA repair proteins clearly limit the replicative lifespan of HSCs [30,62-64]. On the other hand, mitochondrial DNA mutations can promote premature aging phenotypes in blood cells that are distinct from physiological stem cell aging [65]. Other publications further imply that cyclin-dependent kinase inhibitors like p $16^{\text {ink4a }}$ and p21 ${ }^{\mathrm{Cip} / W a f 1}$ are involved in regulating distinct aspects of stem cell aging $[24,66]$. For example, $\mathrm{p} 16^{\mathrm{Ink} 4 \mathrm{a}}$ is elevated in HSCs, neuronal progenitor cells and pancreatic island cells from aged mice, and increased expression of $\mathrm{p} 16^{\mathrm{ink} 4 \mathrm{a}}$ appears partly to contribute to the functional decline of these cell populations as they age $[24,67,68]$. In addition, alteration of p53 activity could affect stem-cell numbers, proliferation potential and hematopoiesis in older organisms, which further supports a model in which aging may be attributed in part to a decline in tissue stem cell regenerative function regulated by p53 activity [69]. To which extent such pathways are functionally interconnected has not been investigated in detail. More interestingly, a role for epigenetic regulation of HSC aging is supported by the apparent involvement of the poly-comb complex genes EZH1, EZH2 and Bmi-1 as well as by data from whole genome gene expression analyses [29,70,71]. EZH1, for example, is a histone methyltransferase important for HSC maintenance over time [72]. Signaling events involving small GTPases were not known to regulate stem cell aging, but recently published studies implicate a critical role for the small Rho GTPase Cdc42 in the aging of HSCs [32].

\section{Cdc42 AND AGING}

Genome-wide association studies of longevity in humans have associated elevated expression of $\mathrm{Cdc} 42$ in hematopoietic cells to increased morbidity and aging [73]. Mice with constitutively elevated Cdc 42 activity in all tissues by genetic deletion of a negative regulator of $\mathrm{Cdc} 42$, Cdc42GAP, displayed a severe premature aging syndrome in multiple tissues [74], including HSCs [36"'], which show reduced adhesion to stroma and reduced polarity due to increased Cdc42 activity in aged HSCs [31-33]. Other phenotypes associated with aged HSCs, including the recently identified loss of cell polarity, appear to be direct consequences of elevated Cdc42 activity in aged HSCs [36"]. These data thus support a hypothesis that elevated $\mathrm{Cdc} 42$ activity and associated signaling pathway plays an important role in the mechanism of HSC aging.

Cdc42 belongs to the Rho family of the Ras GTPase superfamily, acting as a binary molecular switch that cycles between a GTP-bound active state and GDP-bound inactive state in response to a variety of extracellular stimuli [75]. A key function of Cdc42 is regulation of actin cytoskeleton [76], which is believed to be a central mechanism for Cdc42-mediated cell polarization, adhesion and migration. Cdc42 is involved in the induction of actin filopodia and microspikes - at least in part through the effectors PAK, WASP/N-WASP, IQGAP and possibly the Par3/Par6 polarity protein complexes; the Par3/ Par6 complexes are known to regulate actin and tubulin cytoskeleton reorganization and cell polarity (referred to as planar cell polarity in some tissues) [77,78]. Another important function of $\mathrm{Cdc} 42$ is to regulate cell cycle and growth signaling. Cdc42 was found to crosstalk with the JAK-STAT pathway, and to be important for activation of Erk, JNK, p38 
MAP kinases and NF- $\kappa B$ transcription [79-82]. Cdc42-regulated cell proliferation may require phosphorylation of the Cdc42 effector IQGAP1 with subsequent binding to Cdc42. The N-terminus of IQGAP1 interacts with mTOR. Thus, Cdc42 might couple cell growth and division via a Cdc42-IQGAP1-mTOR pathway [83]. On the other hand, hippocampal neuronal polarity is established via an IGF-Cdc42 signaling axis [84]. It is an intriguing possibility that Cdc42 may engage in multiple pathways such as IGF, WNT, mTor and/or JNK that have been previously implicated in aging regulation in mice and other model organisms, and by regulating cytoskeleton polarity machineries mediate the aging-associated decline of HSCs.

\section{STEM CELL REJUVENATION}

It has been reported that aged muscle stem ('satellite') cells, in which an aging phenotype is defective response to Wnt-signaling, can be activated to differentiate and regenerate muscle in aged animals as efficiently as muscle stem cells in young animals - either by forced activation of Notch or by factors in serum from young animals supplied by parabiosis [11,85-87]. Separately, attenuation of HSC aging could also be achieved by lifelong caloric restriction in BalbC inbred mice [88], by anti-oxidative therapy [61] (in the later case, the phenotype of reduced transplantability was ameliorated), or partly by rapamycin treatment [89-91]. These experimental systems suggest different mechanisms of stem cell aging and elucidate the possibility for phenotypic rejuvenation of aged stem cells. Further work studied ex-vivo treatment of aged HSCs, in which Cdc42 activity is significantly elevated compared with young HSCs, with a Cdc 42 activity specific inhibitor. The treatment, which suppressed the Cdc42 activity in chronologically aged HSCs to that found in young HSCs, was able to revert several aging associated phenotypes of aged HSCs as determined by transplantation experiments [36"',92], including lymphoid and myeloid lineage unbalance and HSC fitness. Such treated aged HSCs seemed to be functionally rejuvenated, promoting the hypothesis that aging of HSCs may not be a one-way street and could be pharmacologically reversible.

\section{CONCLUSION}

The molecular mechanisms of HSC aging are beginning to be elucidated. Identifying conditions under which aged HSCs may become functionally similar to young stem cells is the first step towards designing future treatments to restore age-associated imbalances in hematopoiesis and to slow down, halt or alleviate certain aging-related diseases. To this end, a more detailed understanding of signaling pathways such as those regulated by $\mathrm{Cdc} 42$ in aging of HSCs may provide useful clues for translational applications benefiting future stem cell therapies for healthy aging.

\section{Acknowledgments}

We apologize to those authors whose work could not be discussed or referenced owing to space limitations. Our work is supported by grants from the National Institutes of Health, HL076604, DK077762 and AG040118 and the Edward P. Evans foundation, the Deutsche Forschungsgemeinschaft KFO 142, GE2063/1 and SFB 1074, the German Federal Ministry of Education and Research within its joint research project SyStaR, the Excellence program of the Baden-Württemberg foundation and the European Commission (FP7 Marie Curie Initial Training Network MARRIAGE). 


\section{REFERENCES AND RECOMMENDED READING}

Papers of particular interest, published within the annual period of review, have been highlighted as:

- of special interest

- of outstanding interest

Additional references related to this topic can also be found in the Current World Literature section in this issue (p. 392).

1. Christensen K, Doblhammer G, Rau R, Vaupel JW. Ageing populations: the challenges ahead. Lancet. 2009; 374:1196-1208. [PubMed: 19801098]

2. Hayflick L. Intracellular determinants of cell aging. Mech Ageing Dev. 1984; 28:177-185. [PubMed: 6521502]

3. Rubin H. Cell aging in vivo and in vitro [see comments]. Mech Ageing Dev. 1997; 98:1-35. [PubMed: 9255755]

4. Geiger H, Van Zant G. The aging of lympho-hematopoietic stem cells. Nat Immunol. 2002; 3:329333. [PubMed: 11919569]

5. Kirkwood TB. Understanding the odd science of aging. Cell. 2005; 120:437-447. [PubMed: 15734677]

6. Campisi J. Aging and cancer cell biology. Aging Cell. 2008; 7:281-284. [PubMed: 18331618]

7. Geiger H, Rudolph KL. Aging in the lympho-hematopoietic stem cell compartment. Trends Immunol. 2009; 30:360-365. [PubMed: 19540806]

8. Song Z, Ju Z, Rudolph KL. Cell intrinsic and extrinsic mechanisms of stem cell aging depend on telomere status. Exp Gerontol. 2009; 44:75-82. [PubMed: 18640258]

9. Ershler WB, Artz AS, Keller ET. Issues of aging and geriatric medicine: relevance to cancer treatment and hematopoietic reconstitution. Biol Blood Marrow Transplant. 2006; 12:100-106. [PubMed: 16399593]

10. Van Zant G, Liang Y. The role of stem cells in aging. Exp Hematol. 2003; 31:659-672. [PubMed: 12901970]

11. Conboy IM, Conboy MJ, Wagers AJ, et al. Rejuvenation of aged progenitor cells by exposure to a young systemic environment. Nature. 2005; 433:760-764. [PubMed: 15716955]

12. Kirkwood TB. Intrinsic ageing of gut epithelial stem cells. Mech Ageing Dev. 2004; 125:911-915. [PubMed: 15563938]

13. Potten CS, Martin K, Kirkwood TB. Ageing of murine small intestinal stem cells. Novartis Found Symp. 2001; 235:66-79. discussion 79-84, 101-104. [PubMed: 11280034]

14. Kim M, Moon HB, Spangrude GJ. Major age-related changes of mouse hematopoietic stem/ progenitor cells. Ann N Y Acad Sci. 2003; 996:195-208. [PubMed: 12799297]

15. Sudo K, Ema H, Morita Y, Nakauchi H. Age-associated characteristics of murine hematopoietic stem cells. J Exp Med. 2000; 192:1273-1280. [PubMed: 11067876]

16. Geiger H, True JM, De Haan G, Van Zant G. Longevity and stem cells: a genetic connection. Scientific World Journal. 2001; 1:77.

17. Sharpless NE, DePinho RA. Telomeres, stem cells, senescence, and cancer. J Clin Invest. 2004; 113:160-168. [PubMed: 14722605]

18. Torella D, Rota M, Nurzynska D, et al. Cardiac stem cell and myocyte aging, heart failure, and insulin-like growth factor-1 overexpression. Circ Res. 2004; 94:514-524. [PubMed: 14726476]

19. Geiger H, Rennebeck G, Van Zant G. Regulation of hematopoietic stem cell aging in vivo by a distinct genetic element. Proc Natl Acad Sci U S A. 2005; 102:5102-5107. [PubMed: 15788535]

20. Rossi DJ, Bryder D, Zahn JM, et al. Cell intrinsic alterations underlie hematopoietic stem cell aging. Proc Natl Acad Sci U S A. 2005; 102:9194-9199. [PubMed: 15967997] 
21. Ju Z, Jiang H, Jaworski M, et al. Telomere dysfunction induces environmental alterations limiting hematopoietic stem cell function and engraftment. Nat Med. 2007; 13:742-747. [PubMed: 17486088]

22. Rando TA. Stem cells, ageing and the quest for immortality. Nature. 2006 ; 441:1080-1086. [PubMed: 16810243]

23. Mayack SR, Shadrach JL, Kim FS, Wagers AJ. Systemic signals regulate ageing and rejuvenation of blood stem cell niches. Nature. 2010; 463:495-500. [PubMed: 20110993]

24. Janzen V, Forkert R, Fleming HE, et al. Stem-cell ageing modified by the cyclin-dependent kinase inhibitor p16(INK4a). Nature. 2006; 443:421-426. [PubMed: 16957735]

25. Morrison SJ, Wandycz AM, Akashi K, et al. The aging of hematopoietic stem cells [see comments]. Nat Med. 1996; 2:1011-1016. [PubMed: 8782459]

26. Chen J, Astle CM, Harrison DE. Genetic regulation of primitive hematopoietic stem cell senescence. Exp Hematol. 2000; 28:442-450. [PubMed: 10781902]

27. Liang Y, Van Zant G, Szilvassy SJ. Effects of aging on the homing and engraftment of murine hematopoietic stem and progenitor cells. Blood. 2005; 106:1479-1487. [PubMed: 15827136]

28. Linton PJ, Dorshkind K. Age-related changes in lymphocyte development and function. Nat Immunol. 2004; 5:133-139. [PubMed: 14749784]

29. Chambers SM, Shaw CA, Gatza C, et al. Aging hematopoietic stem cells decline in function and exhibit epigenetic dysregulation. PLoS Biol. 2007; 5:e201. [PubMed: 17676974]

30. Rossi DJ, Bryder D, Seita J, et al. Deficiencies in DNA damage repair limit the function of haematopoietic stem cells with age. Nature. 2007; 447:725-729. [PubMed: 17554309]

31. Xing Z, Ryan MA, Daria D, et al. Increased hematopoietic stem cell mobilization in aged mice. Blood. 2006; 108:2190-2197. [PubMed: 16741255]

32. Geiger H, Koehler A, Gunzer M. Stem cells, aging, niche, adhesion and Cdc42: a model for changes in cell-cell interactions and hematopoietic stem cell aging. Cell Cycle. 2007; 6:884-887. [PubMed: 17404508]

33. Kohler A, Schmithorst V, Filippi MD, et al. Altered cellular dynamics and endosteal location of aged early hematopoietic progenitor cells revealed by time-lapse intravital imaging in long bones. Blood. 2009; 114:290-298. [PubMed: 19357397]

34. Humbert PO, Dow LE, Russell SM. The Scribble and Par complexes in polarity and migration: friends or foes? Trends Cell Biol. 2006; 16:622-630. [PubMed: 17067797]

35. Martin-Belmonte F, Perez-Moreno M. Epithelial cell polarity, stem cells and cancer. Nat Rev Cancer. 2012; 12:23-38. [PubMed: 22169974]

36-.. Florian MC, Dorr K, Niebel A, et al. Cdc42 activity regulates hematopoietic stem cell aging and rejuvenation. Cell Stem Cell. 2012; 10:520-530. This article demonstrates that aged HSCs can be rejuvenated by pharmacological inhibition of Cdc42 activity. [PubMed: 22560076]

37-. Ting SB, Deneault E, Hope K, et al. Asymmetric segregation and self-renewal of hematopoietic stem and progenitor cells with endocytic Ap2a2. Blood. 2012; 119:2510-2522. Describes assymetric segregation of a set of proteins upon division of primitive hematopoeitic cells that might be involved in regulation of self-renewal. [PubMed: 22174158]

38. Giebel B. Cell polarity and asymmetric cell division within human hematopoietic stem and progenitor cells. Cells Tissues Organs. 2008; 188:116-126. [PubMed: 18160821]

39. Rajendran L, Beckmann J, Magenau A, et al. Flotillins are involved in the polarization of primitive and mature hematopoietic cells. PLoS One. 2009; 4:e8290. [PubMed: 20027317]

40. Beckmann J, Scheitza S, Wernet P, et al. Asymmetric cell division within the human hematopoietic stem and progenitor cell compartment: identification of asymmetrically segregating proteins. Blood. 2007; 109:5494-5501. [PubMed: 17332245]

41. Wu M, Kwon HY, Rattis F, et al. Imaging hematopoietic precursor division in real time. Cell Stem Cell. 2007; 1:541-554. [PubMed: 18345353]

42-. Ito K, Carracedo A, Weiss D, et al. A PML-PPAR-delta pathway for fatty acid oxidation regulates hematopoietic stem cell maintenance. Nat Med. 2012; 18:1350-1358. Describes a connection between fatty acid oxidation pathways, polarity and regulation of the mode of stem cell divisions. [PubMed: 22902876] 
43. Sengupta A, Duran A, Ishikawa E, et al. Atypical protein kinase C (aPKCzeta and aPKClambda) is dispensable for mammalian hematopoietic stem cell activity and blood formation. Proc Natl Acad Sci U S A. 2011; 108:9957-9962. [PubMed: 21653884]

44. Cheng J, Turkel N, Hemati N, et al. Centrosome misorientation reduces stem cell division during ageing. Nature. 2008; 456:599-604. [PubMed: 18923395]

45. Peng Y, Axelrod JD. Asymmetric protein localization in planar cell polarity: mechanisms, puzzles, and challenges. Curr Top Dev Biol. 2012; 101:33-53. [PubMed: 23140624]

46. Challen GA, Boles NC, Chambers SM, Goodell MA. Distinct hematopoietic stem cell subtypes are differentially regulated by TGF-beta1. Cell Stem Cell. 2010; 6:265-278. [PubMed: 20207229]

47. Beerman I, Bhattacharya D, Zandi S, et al. Functionally distinct hematopoietic stem cells modulate hematopoietic lineage potential during aging by a mechanism of clonal expansion. Proc Natl Acad Sci U S A. 2010; 107:5465-5470. [PubMed: 20304793]

48. Sieburg HB, Cho RH, Dykstra B, et al. The hematopoietic stem compartment consists of a limited number of discrete stem cell subsets. Blood. 2005; 107:2311-2316. [PubMed: 16291588]

49. Cho RH, Sieburg HB, Muller-Sieburg CE. A new mechanism for the aging of hematopoietic stem cells: aging changes the clonal composition of the stem cell compartment but not individual stem cells. Blood. 2008; 111:5553-5561. [PubMed: 18413859]

50. Dykstra B, Olthof S, Schreuder J, et al. Clonal analysis reveals multiple functional defects of aged murine hematopoietic stem cells. J Exp Med. 2011; 208:2691-2703. [PubMed: 22110168]

51. Takubo K, Nagamatsu G, Kobayashi CI, et al. Regulation of glycolysis by Pdk functions as a metabolic checkpoint for cell cycle quiescence in hematopoietic stem cells. Cell Stem Cell. 2013; 12:49-61. [PubMed: 23290136]

52. Warr MR, Binnewies M, Flach J, et al. FOXO3A directs a protective autophagy program in haematopoietic stem cells. Nature. 2013; 494:323-327. [PubMed: 23389440]

53-. Norddahl GL, Wahlestedt M, Gisler S, et al. Reduced repression of cytokine signaling ameliorates age-induced decline in hematopoietic stem cell function. Aging Cell. 2012; 11:1128-1131. This article describes that cytokine signaling ameliorates HSC aging in the context of loss of LNK. [PubMed: 22809070]

54. Vas V, Wandhoff C, Dorr K, et al. Contribution of an aged microenvironment to aging-associated myeloproliferative disease. PLoS One. 2012; 7:e31523. [PubMed: 22363661]

55-. Vas V, Senger K, Dorr K, et al. Aging of the microenvironment influences clonality in hematopoiesis. PLoS One. 2012; 7:e42080. This report illustrates that aging of the microenvironment can influence clonality in hematopoiesis, and thus contribute to stem cell aging. [PubMed: 22879906]

56. Hamilton ML, Van Remmen H, Drake JA, et al. Does oxidative damage to DNA increase with age? Proc Natl Acad Sci U S A. 2001; 98:10469-10474. [PubMed: 11517304]

57. Wang Y, Michikawa Y, Mallidis C, et al. Muscle-specific mutations accumulate with aging in critical human mtDNA control sites for replication. Proc Natl Acad Sci U S A. 2001; 98:40224027. [PubMed: 11274426]

58. Vijg J, Dolle ME. Large genome rearrangements as a primary cause of aging. Mech Ageing Dev. 2002; 123:907-915. [PubMed: 12044939]

59. Martin GM, Ogburn CE, Colgin LM, et al. Somatic mutations are frequent and increase with age in human kidney epithelial cells. Hum Mol Genet. 1996; 5:215-221. [PubMed: 8824877]

60. Ramsey MJ, Moore DH 2nd, Briner JF, et al. The effects of age and lifestyle factors on the accumulation of cytogenetic damage as measured by chromosome painting. Mutat Res. 1995; 338:95-106. [PubMed: 7565886]

61. Ito K, Hirao A, Arai F, et al. Reactive oxygen species act through p38 MAPK to limit the lifespan of hematopoietic stem cells. Nat Med. 2006; 12:446-451. [PubMed: 16565722]

62. Nijnik A, Woodbine L, Marchetti C, et al. DNA repair is limiting for haematopoietic stem cells during ageing. Nature. 2007; 447:686-690. [PubMed: 17554302]

63. Dolle ME, Busuttil RA, Garcia AM, et al. Increased genomic instability is not a prerequisite for shortened lifespan in DNA repair deficient mice. Mutat Res. 2006; 596:22-35. [PubMed: 16472827] 
64. Morales M, Theunissen JW, Kim CF, et al. The Rad50S allele promotes ATM-dependent DNA damage responses and suppresses ATM deficiency: implications for the Mre11 complex as a DNA damage sensor. Genes Dev. 2005; 19:3043-3054. [PubMed: 16357220]

65. Norddahl GL, Pronk CJ, Wahlestedt M, et al. Accumulating mitochondrial DNA mutations drive premature hematopoietic aging phenotypes distinct from physiological stem cell aging. Cell Stem Cell. 2011; 8:499-510. [PubMed: 21549326]

66. Ju Z, Choudhury AR, Rudolph KL. A dual role of p21 in stem cell aging. Ann N Y Acad Sci. 2007; 1100:333-344. [PubMed: 17460196]

67. Molofsky AV, Slutsky SG, Joseph NM, et al. Increasing p16(INK4a) expression decreases forebrain progenitors and neurogenesis during ageing. Nature. 2006; 443:448-452. [PubMed: 16957738]

68. Krishnamurthy J, Ramsey MR, Ligon KL, et al. p16(INK4a) induces an age-dependent decline in islet regenerative potential. Nature. 2006; 443:453-457. [PubMed: 16957737]

69. Dumble M, Moore L, Chambers SM, et al. The impact of altered p53 dosage on hematopoietic stem cell dynamics during aging. Blood. 2007; 109:1736-1742. [PubMed: 17032926]

70. Kamminga LM, Bystrykh LV, de Boer A, et al. The Polycomb group gene Ezh2 prevents hematopoietic stem cell exhaustion. Blood. 2005; 107:2170-2179. [PubMed: 16293602]

71. Park IK, Morrison SJ, Clarke MF. Bmi1, stem cells, and senescence regulation. J Clin Invest. 2004; 113:175-179. [PubMed: 14722607]

72. Hidalgo I, Herrera-Merchan A, Ligos JM, et al. Ezh1 is required for hematopoietic stem cell maintenance and prevents senescence-like cell cycle arrest. Cell Stem Cell. 2012; 11:649-662. [PubMed: 23122289]

73. Kerber RA, O'Brien E, Cawthon RM. Gene expression profiles associated with aging and mortality in humans. Aging Cell. 2009; 8:239-250. [PubMed: 19245677]

74. Wang L, Yang L, Debidda M, et al. Cdc42 GTPase-activating protein deficiency promotes genomic instability and premature aging-like phenotypes. Proc Natl Acad Sci U S A. 2007; 104:1248-1253. [PubMed: 17227869]

75. Etienne-Manneville S, Hall A. Rho GTPases in cell biology. Nature. 2002; 420:629-635. [PubMed: 12478284]

76. Nobes CD, Hall A. Rho, rac, and cdc42 GTPases regulate the assembly of multimolecular focal complexes associated with actin stress fibers, lamellipodia, and filopodia. Cell. 1995; 81:53-62. [PubMed: 7536630]

77. Bishop AL, Hall A. Rho GTPases and their effector proteins. Biochem J. 2000; 348 (Pt 2):241255. [PubMed: 10816416]

78. Kesavan G, Sand FW, Greiner TU, et al. Cdc42-mediated tubulogenesis controls cell specification. Cell. 2009; 139:791-801. [PubMed: 19914171]

79. Lamarche N, Tapon N, Stowers L, et al. Rac and Cdc42 induce actin polymerization and G1 cell cycle progression independently of p65PAK and the JNK/SAPK MAP kinase cascade. Cell. 1996; 87:519-529. [PubMed: 8898204]

80. Coso OA, Chiariello M, Yu JC, et al. The small GTP-binding proteins Rac1 and Cdc42 regulate the activity of the JNK/SAPK signaling pathway. Cell. 1995; 81:1137-1146. [PubMed: 7600581]

81. Minden A, Lin A, Claret FX, et al. Selective activation of the JNK signaling cascade and c-Jun transcriptional activity by the small GTPases Rac and Cdc42Hs. Cell. 1995; 81:1147-1157. [PubMed: 7600582]

82. Perona R, Montaner S, Saniger L, et al. Activation of the nuclear factor-kappaB by Rho, CDC42, and Rac-1 proteins. Genes Dev. 1997; 11:463-475. [PubMed: 9042860]

83. Wang JB, Sonn R, Tekletsadik YK, et al. IQGAP1 regulates cell proliferation through a novel CDC42-mTOR pathway. J Cell Sci. 2009; 122:2024-2033. [PubMed: 19454477]

84. Sosa L, Dupraz S, Laurino L, et al. IGF-1 receptor is essential for the establishment of hippocampal neuronal polarity. Nat Neurosci. 2006; 9:993-995. [PubMed: 16845384]

85. Conboy IM, Conboy MJ, Smythe GM, Rando TA. Notch-mediated restoration of regenerative potential to aged muscle. Science. 2003; 302:1575-1577. [PubMed: 14645852] 
86. Brack AS, Conboy MJ, Roy S, et al. Increased Wnt signaling during aging alters muscle stem cell fate and increases fibrosis. Science. 2007; 317:807-810. [PubMed: 17690295]

87. Liu H, Fergusson MM, Castilho RM, et al. Augmented Wnt signaling in a mammalian model of accelerated aging. Science. 2007; 317:803-806. [PubMed: 17690294]

88. Chen J, Astle CM, Harrison DE. Hematopoietic senescence is postponed and hematopoietic stem cell function is enhanced by dietary restriction. Exp Hematol. 2003; 31:1097-1103. [PubMed: 14585375]

89. Blagosklonny MV. Aging, stem cells, and mammalian target of rapamycin: a prospect of pharmacologic rejuvenation of aging stem cells. Rejuvenation Res. 2008; 11:801-808. [PubMed: 18729812]

90. Chen C, Liu Y, Zheng P. mTOR regulation and therapeutic rejuvenation of aging hematopoietic stem cells. Sci Signal. 2009; 2:ra75. [PubMed: 19934433]

91. Castilho RM, Squarize CH, Chodosh LA, et al. mTOR mediates Wnt-induced epidermal stem cell exhaustion and aging. Cell Stem Cell. 2009; 5:279-289. [PubMed: 19733540]

92. Florian MC, Geiger H. Concise review: polarity in stem cells, disease, and aging. Stem Cells. 2010; 28:1623-1629. [PubMed: 20641041] 


\section{KEY POINTS}

- A defined set of phenotypic and functional features are associated with aged hematopoietic stem cells.

- Aged HSCs, in contrast to young HSCs, present with apolarity.

- The activity of the small RhoGTPase is elevated in aged HSCs, which is at least in part causative for stem cell aging.

- Inhibition of the activity of the small RhoGTPase Cdc42 in aged HSCs to the level reported in young reverses stem cell aging. 